Chapman University

Chapman University Digital Commons

Psychology Faculty Articles and Research

Psychology

3-27-2019

\title{
Oxytocin Receptor Gene (OXTR) and Father Support Interact to Predict Depressive Symptoms Postpartum
}

\author{
Parambir Bhatti \\ Chapman University \\ Taylor Delaney \\ Chapman University \\ Michael Poulin \\ University at Buffalo \\ Jennifer Hahn-Holbrook \\ Chapman University, hahnholb@chapman.edu
}

Follow this and additional works at: https://digitalcommons.chapman.edu/psychology_articles

Part of the Maternal and Child Health Commons, Mental Disorders Commons, Other Psychiatry and Psychology Commons, Psychological Phenomena and Processes Commons, and the Women's Health Commons

\section{Recommended Citation}

Bhatti, P., Delaney, T., Poulin, M., Hahn-Holbrook, J., 2019. Oxytocin receptor gene (OXTR) and father support interact to predict depressive symptoms postpartum. Biological Psychology 147, 107686. https://doi.org/10.1016/j.biopsycho.2019.03.015

This Article is brought to you for free and open access by the Psychology at Chapman University Digital Commons. It has been accepted for inclusion in Psychology Faculty Articles and Research by an authorized administrator of Chapman University Digital Commons. For more information, please contact laughtin@chapman.edu. 


\section{Oxytocin Receptor Gene (OXTR) and Father Support Interact to Predict Depressive Symptoms Postpartum}

\section{Comments}

NOTICE: this is the author's version of a work that was accepted for publication in Biological Psychology. Changes resulting from the publishing process, such as peer review, editing, corrections, structural formatting, and other quality control mechanisms may not be reflected in this document. Changes may have been made to this work since it was submitted for publication. A definitive version was subsequently published in Biological Psychology, volume 147, in 2019. DOI: 10.1016/j.biopsycho.2019.03.015

The Creative Commons license below applies only to this version of the article.

\section{Creative Commons License}

\section{(c) $(7) \Theta$}

This work is licensed under a Creative Commons Attribution-Noncommercial-No Derivative Works 4.0 License.

\section{Copyright}

Elsevier 


\section{Accepted Manuscript}

Title: Oxytocin Receptor Gene (OXTR) and Father Support Interact to Predict Depressive Symptoms Postpartum

Authors: Parambir Bhatti, Taylor Delaney, Michael Poulin, Jennifer Hahn-Holbrook

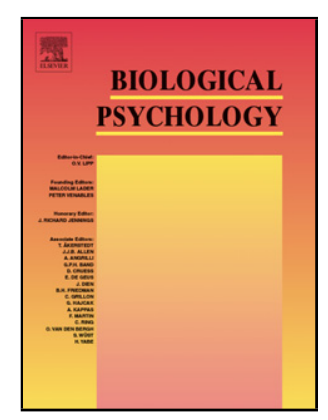

PII:

S0301-0511(18)30122-4

DOI: https://doi.org/10.1016/j.biopsycho.2019.03.015

Reference: BIOPSY 7686

To appear in:

Received date: $\quad 12$ February 2018

Revised date: $\quad 26$ March 2019

Accepted date: $\quad 26$ March 2019

Please cite this article as: Bhatti P, Delaney T, Poulin M, Hahn-Holbrook J, Oxytocin Receptor Gene (OXTR) and Father Support Interact to Predict Depressive Symptoms Postpartum, Biological Psychology (2019), https://doi.org/10.1016/j.biopsycho.2019.03.015

This is a PDF file of an unedited manuscript that has been accepted for publication. As a service to our customers we are providing this early version of the manuscript. The manuscript will undergo copyediting, typesetting, and review of the resulting proof before it is published in its final form. Please note that during the production process errors may be discovered which could affect the content, and all legal disclaimers that apply to the journal pertain. 
OXTR, SOCIAL SUPPORT \& POSTPARTUM DEPRESSION

Oxytocin Receptor Gene (OXTR) and Father Support Interact to Predict Depressive Symptoms Postpartum

Parambir Bhatti $^{\mathrm{a}, \mathrm{c}}$, Taylor Delaney ${ }^{\mathrm{a}, \mathrm{c}}$, Michael Poulin $^{\mathrm{b}}$, Jennifer Hahn-Holbrook ${ }^{\mathrm{a}, \mathrm{d}}$

${ }^{a}$ Chapman University, Department of Psychology, One University Drive, Orange, California 92866, USA.

${ }^{\mathrm{b}}$ University at Buffalo, Department of Psychology, Park Hall 206, Buffalo, NY 14260, USA.

${ }^{c}$ A.T. Still University, School of Osteopathic Medicine, 5850 East Still Circle, Mesa, Arizona 85206, USA.

${ }^{\mathrm{d}}$ University of California, Merced, Department of Psychology, 5200 Lake Road, Merced, California 95340, USA.

${ }^{*}$ Correspondence regarding this manuscript can be addressed to J. Hahn-Holbrook at:

5200 N Lake Road, Merced, CA 95323. Email: jhahn-holbrook@ucmerced.edu

\title{
Highlights
}

- $\quad$ OXTR rs53576 SNP moderated the effect of father support on PPD symptoms

- Father support was most protective for mothers with the GG genotype

- Father support was a stronger predictor of PPD symptoms than mother or family support

- The stress-buffering effect of father support was only found in GG genotype mothers

\begin{abstract}
Postpartum depression (PPD) is a debilitating mental illness affecting approximately $13 \%$ of mothers after birth. Both genetic and psychosocial factors contribute to PPD risk, but very little is known about how these factors interact. We tested whether the rs53576 polymorphism in the oxytocin receptor $(O X T R)$ gene accounts for variation in the impact of low social support
\end{abstract}


OXTR, SOCIAL SUPPORT \& POSTPARTUM DEPRESSION

as a risk factor for depression among mothers during the perinatal period. New mothers $(N=$ 220) provided saliva or blood DNA samples and completed surveys assessing PPD symptoms and perceived social support. In a significant interaction, social support from the baby's father predicted PPD symptoms to a greater extent among mothers with the GG compared to AG and AA genotypes. These results add to converging evidence that variation in OXTR rs53576 moderates the impact of the social environment on PPD.

Keywords: Postpartum depression, Social support, Oxytocin receptor gene, rs53576

\section{Introduction}

Postpartum depression (PPD) is a prevalent mental health disorder suffered by approximately $13 \%$ of women in the United States and 17\% of women globally (Hahn-Holbrook, Cornwell-Hinrichs \& Anaya, 2018; O'Hara et al., 1996). The majority of cases of PPD go undiagnosed (Dennis \& Chung-Lee, 2006) and even mild or moderate symptoms of depression are deleterious for mothers and potentially harmful to the infant and the family (Brummelte \& Galea, 2016; Netsi et al., 2018). PPD is diagnosed through clinical interviews, although selfreport questionnaires are more commonly used to measure depressive symptoms (Yim et al., 2015). ${ }^{1}$ Given the consequences of PPD and its symptoms, hundreds of studies have examined biological and psychological risk factors.

Poor social support numbers among the most consistent risk factors for PPD symptoms (for a review, see, Yim et al., 2015). Indeed, individuals who report higher levels of social support live longer and are at reduced risk of depression, among many other stress-related 


\section{OXTR, SOCIAL SUPPORT \& POSTPARTUM DEPRESSION}

maladies such as diabetes, cardiac illness, or infection (for review, see Holt-Lunstad et al., 2010). Social support is thought to convey health benefits both directly, through its ability to elevate mood, and indirectly by buffering individuals against stress-induced wear and tear on the body (Cohen \& Wills, 1985; for a review, see Uchino, 2006). Social support appears particularly vital during the postpartum period, as a meta-analysis of 59 studies of 12,810 postpartum women identified poor social support as one of the strongest predictors of PPD symptoms (O'Hara et al., 1996), with comparable results obtained in a larger and more recent meta-analysis of over 70 studies encompassing approximately 25,000 postpartum mothers (Robertson et al., 2004). Subjective perceptions of oneself as the beneficiary of social support, distinct from objective metrics, have been found particularly protective against PPD symptoms (Yim et al., 2015). Although the perceived support of family and friends also appears beneficial, feeling supported by the baby's father may hold special significance. For example, in a study of 12,361 postpartum Australian women, Milgrom and colleagues (2008) found that social support from the mother's partner protected against PPD symptoms to a greater extent than support from other family members. In consideration of these prior findings, and of the clear functional relevance of partner support to successful parenting, we anticipated that any observed relationships between oxytocin mechanisms and social support would be particularly evident with regard to father support.

The neuropeptide hormone oxytocin facilitates social relationships in humans and other mammals (Carter \& Keverne, 2002; Insel, 2010; McCall \& Dinger, 2012), attuning the brain to the social world (Bartz, 2016) and helping to biologically mediate the attenuating effects of affiliation on anxiety (e.g., Labuschagne et al., 2010; Windle, Shanks, Lightman, \& Ingram, 1997). Oxytocin administration can bolster trust, empathy and interpersonal communication in affiliative contexts (Kosfeld et al., 2005; Domes et al., 2007; Ditzen et al., 2009). Conversely, 


\section{OXTR, SOCIAL SUPPORT \& POSTPARTUM DEPRESSION}

oxytocin appears to heighten feelings of exclusion when social support is perceived to be absent (Bartz, 2016).

Individual differences in social functioning have been linked to genetic variation in the oxytocin receptor system (Thompson, Parker, Hallmayer, Waugh, \& Gotlib, 2011). Single nucleotide polymorphisms (SNPs) in the OXTR gene modulate the activity and peptide binding abilities of circulating levels of oxytocin in the body. A growing body of research has focused on one SNP in particular-rs53576. Polymorphisms in rs53576 involve a guanine $(\mathrm{G})$ to adenine (A) substitution in the third intron of the OXTR gene. Because people inherit one copy of this SNP from each parent, an individual's genotype can be homozygous for the A allele (AA), heterozygous (GA), or homozygous for the G allele (GG). Variations in rs53576 have been found to correlate with the volume of the hypothalamus and the functional and structural connectivity of the hypothalamus to the amygdala and the dorsal anterior cingulate cortex (Tost et al., 2010), regions implicated in PPD-relevant outcomes such as social distress and stress reactivity (see Saphire-Bernstein et al., 2011, for a review).

Consistent with the hypothesized role of oxytocin, variation in rs53576 has been linked to key social cognitive functions (for reviews, see Gong et al., 2017; Li et al., 2015). For example, the number of $\mathrm{G}$ alleles ( 0 to 2 ) someone carries positively correlates with parental sensitivity (Bakersman-Kranenburg and van Ijzendoorn, 2008), attachment security (Chen et al, 2011), emotion detection (Rodrigues et al., 2009), prosocial behavior (Poulin, Holman, \& Buffone, 2012), optimism and self-esteem (Saphire-Bernstein et al., 2011, but see Cornelis et al., 2012 for a null result). However, in adverse social contexts, rs53576 G allele carriers may be vulnerable to adverse outcomes. For instance, in a study of 288 university students, McQuaid and colleagues (2013) found that maltreatment in early life resulted in higher levels of depressive 


\section{OXTR, SOCIAL SUPPORT \& POSTPARTUM DEPRESSION}

symptoms among G allele carriers (GG/GA genotypes), whereas AA genotypes exposed to comparable maltreatment evinced no such association, and Bradley et al. (2013) obtained similar results for G carriers in a study of 971 African-American adults living in unstable homes with low levels of familial support. Together, these overall findings suggest that new mothers with rs53576 G alleles may be more attuned to the social world, and hence either relatively protected or more susceptible to PPD symptoms contingent on their social circumstances.

Here, we assessed whether rs53576 moderates the association between low social support (particularly from fathers) and PPD symptoms. We predicted that the presence of $\mathrm{G}$ alleles would predict a new mother's sensitivity to the quality of social support she receives. In light of prior research, we further predicted that father support would be more protective against PPD symptoms than family support (Milgrom et al., 2008). We tested the number of $\mathrm{G}$ alleles (rather than dichotomously contrasting 'GG versus other' or 'AA versus other') to reduce errors associated with erroneously assuming allele dominance (e.g., Bradley et al., 2011; Ludmer et al., $2015 ; 2017$ ) that appear to have contributed to problems in past candidate gene research (Duncan \& Keller, 2011). In a complementary prediction, we also tested whether individuals homozygous for the A allele in rs53576 would report higher levels of depressive symptoms in comparison to those carrying the G allele given a previous report (see Saphire-Bernstein et al., 2011). Although our a priori predictions concern only rs53576, we also explored the effects of another OXTR polymorphism, rs2268498, linked to pregnancy and difficult labor (Algovik, Kivinen, Peterson, Westgren, \& Kere, 2010).

\section{Methods}

\subsection{Participants}




\section{OXTR, SOCIAL SUPPORT \& POSTPARTUM DEPRESSION}

A total of 224 perinatal mothers were recruited from farmers' markets, shopping malls, and mother-infant classes in Orange County, California. To be eligible for the study, participants had to be English- or Spanish-speaking, at least 18 years of age, have an infant under the age of 12 months, not be taking any steroid medications, and not have any previous or current diagnosis of polycystic ovarian syndrome. Four mothers failed to complete the survey packet, leaving a final sample of 220 (53\% White, 28\% Latina, 11\% Asian, 1\% African-American/Black, 7\% Other or More than one). Seven participants had mothers who were deceased and so did not fill out the maternal support scale, leaving a sample of 213 for analyses involving perceived mother support. Ninety-six percent of the sample was married or living with a partner at the time of data collection.

\subsection{Experimental procedure}

Once signed informed consent was obtained, participants were provided with a series of questionnaires assessing demographic information (including age, marital status, and income; see Table 1), levels of perceived support, and postpartum depressive symptoms. For the majority of mothers in the study, survey data and saliva samples for DNA genotyping were collected at the field recruitment site. A subset of the sample $(\mathrm{N}=23)$ recruited to participate in an unrelated pilot laboratory study filled out the survey materials online prior to their laboratory session, where they provided blood samples for DNA genotyping. Participant data obtained in the field versus the lab did not differ in terms of social support, depressive symptoms, OXTR G allele frequency, or demographic factors, and are therefore combined for all analysis. Upon completion of the study, participants were debriefed and compensated with $\$ 5$ cash or a $\$ 10$ gift certificate to a local baby boutique. All procedures were approved by the Chapman University Institutional Review Board. 


\section{OXTR, SOCIAL SUPPORT \& POSTPARTUM DEPRESSION}

\subsection{Measures}

Perceived social support. Separate seven-item scales were employed to assess the degree of perceived social support from family, the mother's mother, and the baby's father, respectively (Turner et al., 1990). The scales each consisted of statements such as: "No matter what happens, I know that my [family/mother/baby's father] will always be there for me if I need them"; "Sometimes I'm not sure if I can completely rely on the [family/mother/baby's father] [reverse coded]"; "I know my [family/mother/baby's father] will always stand by me." These items were rated on a 4-point Likert scale ranging from 1 (strongly disagree) to 4 (strongly agree); ratings for each scale were calculated by summing the items, yielding a potential range of 7 to 28 , with higher scores indicating greater perceived social support (mother support $\alpha=.89$, family support $\alpha=.87$, father support $\alpha=.91$ ). This social support measure has been validated for use with pregnant and postpartum mothers, and was previously found to correlate with PPD symptoms (Turner et al., 1983; Collins et al., 1993; Feldman et al., 2000; Hahn-Holbrook et al., 2013). Maternal, father and family social support measures were assessed as individual predictors; a composite measure was also created by z-scoring these three scores and averaging them to create a measure of overall social support (Cronbach's alpha $\alpha=.90$ ).

Postpartum depressive symptoms. The ten-item Edinburgh Postnatal Depression Scale (EPDS; Cox et al., 1987; Wisner et al., 2002) was utilized to assess participants' degree of depressive symptoms with regard to mood, anxiety, guilt, sleep issues, and thoughts of self-harm during the past week according to 4-point (0 to 3) scales worded to suit each item, with higher scores indicate greater symptoms of depression. These ratings are summed, yielding a sum score ranging from 0 to $30(\alpha=.84)$ which may be used as a continuous variable to assess the severity of depressive symptoms (Cox et al., 1987). ${ }^{2}$ 


\section{OXTR, SOCIAL SUPPORT \& POSTPARTUM DEPRESSION}

Perceived stress. Perceived general life stress was measured according to the Perceived Stress Scale (PSS; Cohen et al., 1983) as a potential confounding variable because perceived stress correlates with both social support and PPD symptoms (see Yim et al., 2015, for a review). This ten-item measure utilizes a 5-point scale (0 to 4); all ratings are summed, yielding a potential range of 0 to $40(\alpha=.89)$, with higher scores indicating more perceived stress.

Genotyping. DNA was collected via both saliva and blood, yielding similar results (James, Panford-Walsh, Birnboim, \& Iwasiow, 2013). Genomic DNA was extracted from saliva using Sequenom/Agena iPLEX genotyping procedures; genomic DNA was extracted from whole blood samples using the QIAamp 96 DNA Blood kit according to the manufacturer's instructions, save that the initial sample of blood was scaled up to $300 \mu \mathrm{L}$ (Qiagen). The OXTR rs53576 and rs2268498 SNPs were genotyped using MassARRAY genotyping technology (Sequenom/Agena), resulting in the genotypes AA, AG, and GG for rs53576 and CC, CT, and TT for rs 2268498 .

\subsection{Analytic Strategy}

Covariate analysis. Preliminary analyses were carried out to identify potential confounding variables. Previous research, for example, has demonstrated that peoples of Asian descent are less likely to carry the rs53576 G allele than people of European or Hispanic descent (Butovskaya et al., 2016; Kim et al., 2010), that Asians living in the US report lower levels of psychosocial resources, and that psychological reactions to social support can vary by race and ethnicity (Kim et al., 2010; Mojaverian \& Kim, 2013). Accordingly, we sought to rule out the possibility that any apparent effects of the rs53576 polymorphism might owe to race/ethnicity. We likewise tested whether demographic factors, levels of social support, or PPD symptoms differed as a function of $O X T R$ genotype. Variables that differed at the level of $p<.10$ as a 


\section{OXTR, SOCIAL SUPPORT \& POSTPARTUM DEPRESSION}

function of OXTR variants, or that significantly correlated with social support, were included as covariates in the moderation analysis. Linear regressions were used in analyses involving continuous outcome variables and binary logistic regressions were used for categorical variables.

Social support analysis. Pearson's correlations were utilized to test whether support from family, the mother, and/or the baby's father were associated with PPD symptoms individually. Next, to explore whether each form of social support was a unique predictor of PPD symptoms, all three sources of social support were included in a multivariate linear regression model.

Moderation analysis. Multivariate linear regression was used to assess whether the rs53576 genotype moderated the relationship between social support and depressive symptoms postpartum. Similar exploratory analyses were conducted for rs 2268498 , however, we had no $a$ priori predictions for this polymorphism. Cross products were created between rs53576 and rs2268498 genotypes (coded as number of $\mathrm{G}$ or $\mathrm{T}$ alleles carried, respectively; i.e. 0,1 or 2) and each of the social support measures. These cross products were then regressed on PPD symptoms in combination with the target $O X T R$ polymorphism and the corresponding social support variable. A moderation model for the composite support measure was conducted first, followed by separate models for father, mother, and family support. All variables were checked for normality of distribution before analysis, revealing that social support from the baby's father and family were both positively skewed. Accordingly, these variables were reverse log-transformed before analysis to improve the normality of these distributions. (Follow-up analyses were also run using the non-transformed variables. The pattern of results using the raw data did not differ from log-transformed models.) 
OXTR, SOCIAL SUPPORT \& POSTPARTUM DEPRESSION

\section{Results}

\section{Preliminary Analyses}

Table 1 reports demographic information on this sample and levels of support and PPD symptoms for each rs53576 and rs2268498 genotype. Analyses indicated that these genotypes were in Hardy-Weinberg equilibrium. Levels of PPD symptoms did not differ as a function of rs53576 ( $p=.11)$ or rs2268498 $(p=.22)$ genotype. Mothers with a CT genotype on rs2268498 reported more perceived family support than mothers with a CC genotype. Women who were married to the infant's father reported higher levels of perceived support from family and the baby's father compared to those who were not. There were too few Black mothers to perform racial and ethnic statistical comparisons; however, these mothers were included in all other analysis. White participants had more G alleles on rs53576 than did Hispanic or Asian participants $(p=.01)$. Asian participants had more A alleles on rs2268498 than White $(p<.01)$ or Hispanic mothers $(p<.05)$. Furthermore, White participants reported significantly higher levels of support from the baby's father than did Hispanic or Asian participants, $p s<.03$. White participants likewise reported more family support than Hispanic participants, $p=.02$, but not Asian participants. Consistent with the well-established relationship between stress and social support, perceived stress was inversely correlated with all three support variables. Given the potentially confounding differences with regard to PPD symptom outcomes orthogonal to rs53576 status, ethnicity/race (White as the contrast reference group), marital status, and perceived stress were included as covariates in all subsequent moderation analysis.

\section{Social Support Analyses}

As predicted, and consistent with previous research, social support from family, the mother, and the baby's father were all inversely correlated with PPD symptoms (see Table 2). To 


\section{OXTR, SOCIAL SUPPORT \& POSTPARTUM DEPRESSION}

ascertain which form of social support was most protective, we entered the three sources of social support into a multivariate linear regression model. As anticipated, only father support was a unique predictor of PPD symptoms $(\mathrm{B}=-1.97, S E=0.89, \beta=-0.17, p=.03,95 \% \mathrm{CI}[-3.72$, 0.21]) when included alongside mother $(\mathrm{B}=-1.82, \mathrm{SE}=1.41, \beta=-0.10, p=.20,95 \% \mathrm{CI}[-4.60$, $0.96])$ and family support $(\mathrm{B}=-1.66, S E=1.00, \beta=-0.14, p=.10,95 \% \mathrm{CI}[-3.63,0.31])$ in the regression model.

\section{OXTR rs53576 Moderation Analyses}

Total Support. We tested whether OXTR rs53576 moderated the relationship between the composite social support measure (comprised of the average support from father, mother, and family) and depressive symptoms in a regression model. There was a non-significant interaction $(p=.07)$ between the composite support measure and OXTR rs53576 $(\mathrm{B}=0.73, \mathrm{SE}=0.41, \beta=-$ $.24,95 \%$ CI $[-.07,1.54], r^{2}$ change= 0.01$)$. Nonetheless, given the appearance of a trend, we explored the simple slopes association between total support for each genotype. Total support predicted $10.5 \%$ of the variance in PPD symptoms for GG carriers $(\mathrm{B}=-1.96, S E=0.65, \beta=-$ $0.32, p=.003,95 \% \mathrm{CI}[-3.25,-0.67]), 12.0 \%$ for $\mathrm{AG}$ carriers $(\mathrm{B}=-2.06, S E=0.56, \beta=-0.35, p$ $<.001,95 \% \mathrm{CI}[-3.17,-0.95])$, and only $0.02 \%$ for AA carriers $(\mathrm{B}=-0.27, S E=0.92, \beta=-0.05$, $p=.77,95 \% \mathrm{CI}[-2.13,1.59])$. Categorical slopes comparisons confirmed that the relationship between total support and PPD symptoms was significantly stronger in the GG group than the AA group $(p=.019)$, whereas the AG group did not significantly differ from either the AA $(p<$ $.076)$ or the GG group $(p=.916)$.

Father Support. We next assessed our primary moderation prediction regarding perceived support from the baby's father. As anticipated, the rs53576 polymorphism significantly moderated the association between baby's father support and PPD symptoms 


\section{OXTR, SOCIAL SUPPORT \& POSTPARTUM DEPRESSION}

(interaction term: $\mathrm{B}=2.32, S E=0.79, \beta=0.52, p=.004,95 \% \mathrm{CI}[0.77,3.88], r^{2}$ change $=.02$; see Figure 1). Simple slopes analyses indicated that, for GG genotypes, perceived support from the baby's father predicted approximately $10.3 \%$ of the variance in PPD symptoms $(B=-3.67$, $S E=1.27, \beta=-.33, p=.005,95 \% \mathrm{CI}[-6.20,-1.15])$. In AG genotypes, father support predicted $6.1 \%$ of the variance in PPD symptoms $(\mathrm{B}=-3.03, S E=1.23, \beta=-.24, p=.02,95 \% \mathrm{CI}[-5.48,-$ 0.58]). In AA genotypes, father support was not significantly related to PPD symptoms ( $\mathrm{B}=-$ 1.09, $S E=1.90, \beta=-.10, p=.57,95 \%$ CI [-4.95, 2.77], $\left.r^{2}=.01\right)$. Categorical slopes comparisons showed that the relationship between father support and PPD symptoms was significantly stronger in the GG group than the AG $(p=.039)$ or the AA groups $(p=.002)$, while the AG and AA groups did not significantly differ from each other $(p=.297){ }^{3}$

Three-way interaction between stress, father support, and OXTR rs53576. In order to better understand the role of stress in our results, we examined the possibility that the interactive effects of social support and rs53576 would be strongest when mothers reported high (compared to low) stress, consistent with the stress-buffering hypothesis (Cohen \& Willis, 1985; Uchino, 2006). In an exploratory analysis, we tested the potential three-way interaction between perceived stress, father support and OXTR genotype. We z-scored father support and perceived stress, and then included stress, father support, rs53576 and a three-way cross-product interaction term (along with the four possible two-way cross-products) in a regression model predicting PPD symptoms. We detected a significant three-way interaction between perceived stress, father support and rs53576 $\left(\mathrm{B}=0.83, S E=0.31, \beta=.35, p=.008,95 \%\right.$ CI $[.22,1.44], r^{2}$ change $=$ 0.014). In GG genotypes, the inverse relationship between father support and PPD symptoms was indeed stronger when women reported higher (compared to lower) perceived stress ( $\mathrm{B}=$ $.651, S E=0.25, \beta=-.17, p=.010,95 \%$ CI $[-1.14,-0.16], r^{2}$ change $\left.=0.03\right)$. No such buffering 


\section{OXTR, SOCIAL SUPPORT \& POSTPARTUM DEPRESSION}

interactions between perceived stress and father support were observed in the $\mathrm{AG}(\mathrm{B}=.11, S E=$ $0.39, \beta=.03, p=.760,95 \% \mathrm{CI}[-0.65,0.88], r^{2}$ change $\left.=-0.006\right)$ or AA genotype groups $(B=$ $1.16, S E=0.59, \beta=.23, p=.061,95 \%$ CI $[-.058,2.37], r^{2}$ change $\left.=.04\right)$.

Mother Support. We examined interactions between mother support and OXTR rs53576. The rs53576 genotype did not significantly moderate the effect of maternal support on PPD symptoms $\left(\mathrm{B}=.20, S E=0.31, \beta=.09, p=.506,95 \% \mathrm{CI}[-.40, .80], r^{2}\right.$ change $\left.=-.001\right)$.

Family Support. We tested the interaction between family support and OXTR rs53576. The rs53576 genotype did not significantly moderate the effect of family support on PPD symptoms $\left(\mathrm{B}=-.017, \mathrm{SE}=0.32, \beta=-.01, p=.958,95 \% \mathrm{CI}[-.65, .62], r^{2}\right.$ change $\left.=-.002\right)$.

\section{rs2268498 Analyses}

Participants' rs2268498 genotype did not moderate the effect of social support (either the composite measure $[p=.366]$ nor father $[p=.543]$, mother $[p=.158]$, or family support $[p=$ .612], individually) on PPD symptoms.

\section{Discussion}

The present results indicate that OXTR genotype moderates the strength of the association between social support from the baby's father and PPD symptoms. Specifically, we found that PPD symptoms were more tightly linked to the social support mothers received from the baby's father in the GG genotype group relative to mothers with AG or AA genotypes. Consistent with the hypothesized role of oxytocin in heightening the impact of both social affiliation and exclusion on mental health outcomes, GG homozygotes (and to a lesser extent, AG heterozygotes) displayed more PPD symptoms when father support was perceived to be low, whereas no such association obtained for AA homozygotes. 


\section{OXTR, SOCIAL SUPPORT \& POSTPARTUM DEPRESSION}

The general consensus in the $O X T R$ literature is that individuals carrying one or more $\mathrm{G}$ alleles for rs53576 are more sensitive to their social environments than those carrying A alleles (Bradley et al., 2013; Chen et al., 2011; Hostinar et al., 2014; McQuaid et al., 2013; Riem et al., 2011; Sturge-Apple et al., 2012). For example, individuals with one or two copies of the $\mathrm{G}$ allele of rs53576 have been found to evince lower cortisol responses to stress after social support when compared to individuals with the same genotype who received no social support (Chen et al., 2011). Relatedly, Sturge-Apple and colleagues studied 201 mothers with young toddlers and found that inter-parental conflict was more likely to 'spill over' and result in decreased maternal sensitivity and increased punitive parenting in GG homozygotes than in AA/AG genotypes.

Our multiple regression including maternal and family support revealed that support from the baby's father drove the inverse correlation between perceived social support and low PPD symptoms as well as uniquely interacting with rs53576. Perceived deficiencies in the social support provided by the baby's father may be particularly critical predictors of maternal distress in the postpartum period given the shared responsibility and vital need for cooperation between parents (Milgrom et al., 2008). The transition to parenthood is often associated with sudden deterioration in marital relationship quality (Doss, Rhoades, Stanley et al., 2009). Our research suggests that such declines could be especially deleterious for women who are more socially attuned as a function of their OXTR gene variants. In turn, the partners of mothers possessing such variants may be at greater risk of depressive symptoms themselves as an indirect consequence, given that partners' mental health tracks the postpartum mental health of mothers, with partners of mothers with PPD $30 \%$ more likely to be depressed themselves (Iles et al., 2011). Future research might explore whether partners of mothers with more socially sensitive 


\section{OXTR, SOCIAL SUPPORT \& POSTPARTUM DEPRESSION}

OXTR variants do indeed report greater depressive symptoms under contexts of relationship discord.

Consistent with the stress-buffering hypotheses, exploratory analysis in this study revealed that the association between father support and rs53576 was further moderated by perceived stress. Namely, in mothers with GG genotypes, social support was a more potent buffer against PPD symptoms when mothers reported higher (compared to lower) levels of perceived stress. There was no evidence of such a stress buffering effect in the larger group of AG mothers or the smaller group of AA mothers. However, these exploratory analyses should be interpreted with caution given that studies testing stress buffering models typically utilize more objective measures of stress exposure (e.g., major life event inventories), rather than the perceived stress scale used here. Our perceived stress measure shared approximately half of its variance with PPD symptoms $\left(r^{2}=.51\right)$, which is slightly higher than meta-analytic estimates of the shared variance using life events inventories $\left(r^{2}=.38-.40\right.$; Beck, 2001). We controlled for perceived stress in all of our moderation analyses because stress not only covaries with PPD symptoms, but also with social support and demographic variables relevant to OXTR variation (e.g., race/ethnicity), and hence introduces noise likely to obscure relationships between social support and OXTR. Perceived stress is characterized by feelings of inability to cope with life's challenges, but not necessarily with affective states associated with depression such as low mood and anhedonia. As such, controlling for perceived stress in our moderation analyses may have particularly highlighted the interaction between $O X T R$ and support with regard to aspects of PPD symptoms which are distinct from perceived stress.

The results of this study should be interpreted cautiously in light of several limitations. First, our sample size of 220, while sufficient to detect the relationships reported, is smaller than 


\section{OXTR, SOCIAL SUPPORT \& POSTPARTUM DEPRESSION}

the ideal participant pool for genetic studies (Duncan \& Keller, 2011). A larger sample may have detected the significant relationships between the OXTR genotype and PPD symptoms reported in previous studies (Saphire-Bernstein et al., 2011). Second, we administered a selfreport continuous scale of depressive symptoms rather than assessing mothers clinically diagnosed with PPD, diminishing the generalizability of our findings to clinical populations. Third, we have not elucidated the potential mechanisms linking OXTR variation with PPD symptom outcomes. OXTR SNPs may influence PPD symptoms via a number of processes, including downstream effects on oxytocin receptor expression (Mizumoto, Kimura, \& Ivell, 1997), or covarying linkages with other SNPs not assessed here (Lin, Vance, Pericak-Vance, \& Martin, 2007). Highly powered studies might explore whether other OXTR SNPs (for example, rs2254298; Thompson et al., 2011) or other genetic variants (such as those related to the release of oxytocin) moderate the relationship between perceived social support and maternal mental health. Future work directed toward identifying mediating mechanisms might also explore the extent to which variations in $O X T R$ determine the extent to which natural shifts in oxytocin associated with childrearing impact postpartum depression symptoms and maternal behavior. For example, if mothers who carry G alleles for OXTR 53576 are more sensitive to the actions of oxytocin, then events associated with exposure to natural doses of oxytocin such as vaginal childbirth (compared to C-section) or breastfeeding (compared to formula-feeding) may be more important predictors of PPD symptoms or maternal bonding in mothers who carry $\mathrm{G}$ alleles.

To the best of our knowledge, the present study is the first to explore how social and genetic factors interact to predict PPD symptoms. Looking ahead, understanding of the etiology of PPD symptoms may be advanced by similar efforts to synthesize literatures across disciplinary boundaries to create biopsychosocial models of PPD (for a review, see Yim et al., 
OXTR, SOCIAL SUPPORT \& POSTPARTUM DEPRESSION

2015). By determining which varieties of social support affect which sorts of

postpartum mothers, we may one day be able to craft personalized interventions to prevent and ameliorate PPD.

\section{Acknowledgments}

We are grateful to our community partners, Granola Babies Boutique and MOMS of Orange County, as well as to our research assistants, Shiva Amanat, Mariel Barojas, Maddisen Espeseth, Samantha Halela, Nikki Shahbazi, and Bonnie Truong. We are also grateful to Chapman University's Office of Undergraduate Research and the Biology Honor Society (TriBeta) for providing grant support for this project.

\section{Declaration of Conflicting Interests}

The authors have no conflicts of interest to declare. 


\section{OXTR, SOCIAL SUPPORT \& POSTPARTUM DEPRESSION}

\section{Footnotes}

${ }^{1}$ For the purposes of this paper, we reserve the term PPD for clinically diagnosed cases; otherwise, in regard to studies that rely on self-report screeners, we refer to PPD symptoms.

${ }^{2}$ We also included a single-item dichotomous (Yes/No) self-report measure of prior history of depression, "Have you ever experienced depression during your lifetime?" as a potentially relevant covariate. Follow-up tests confirmed that including history of self-reported depression did not change the statistical significance of any of the analyses reported here, although depression history did predict PPD symptoms $(\mathrm{B}=2.14, S E=0.64, \beta=.23, p=.001$, $95 \%$ CI $\left.[.87,3.40], r^{2}=.05\right)$.

${ }^{3}$ We conducted follow-up tests to assess whether father support might exert a different impact on PPD symptoms according to race/ethnicity. Tests revealed that the race/ethnicity $\mathrm{x}$ father support interaction term was not statistically significant, nor did including this term change our pattern of results with regard to rs53576 moderating the effects of father support on PPD symptoms. Moreover, removing the race/ethnicity covariates from the models altogether also did not change the pattern of results. 


\section{OXTR, SOCIAL SUPPORT \& POSTPARTUM DEPRESSION}

\section{References}

Algovik, M., Kivinen, K., Peterson, H., Westgren, M., \& Kere, J. (2010). Genetic evidence of multiple loci in dystocia-difficult labour. BMC Medical Genetics, 11, 105.

Bartz, J. A. (2016). Oxytocin and the pharmacological dissection of affiliation. Current Directions in Psychological Science, 25(2), 104-110.

Beck, C. T. (2001). Predictors of postpartum depression: an update. Nursing research, 50(5), 275-285.

Bradley, B., Davis, T. A., Wingo, A. P., Mercer, K. B., \& Ressler, K. J. (2013). Family environment and adult resilience: contributions of positive parenting and the oxytocin receptor gene. European Journal of Psychotraumatology, 4, 10.3402/ejpt.v4i0.21659. doi:10.3402/ejpt.v4i0.21659

Brummelte, S., Chau, C. M., Cepeda, I. L., Degenhardt, A., Weinberg, J., Synnes, A. R., \& Grunau, R. E. (2015). Cortisol levels in former preterm children at school age are predicted by neonatal procedural pain-related stress. Psychoneuroendocrinology, 51, 151163.

Brummelte, S., \& Galea, L. A. (2016). Postpartum depression: etiology, treatment and consequences for maternal care. Hormones and behavior, 77, 153-166.

Buffone, A. E., \& Poulin, M. J. (2014). Empathy, target distress, and neurohormone genes interact to predict aggression for others-even without provocation. Personality and Social Psychology Bulletin, 40(11), 1406-1422.

Butovskaya, P. R., Lazebny, O. E., Sukhodolskaya, E. M., Vasiliev, V. A., Dronova, D. A., Fedenok, J. N., Rosa, A., Peletskaya, E. N., Ryskov, A. P., \& Butovskaya, M. L. (2016). 


\section{OXTR, SOCIAL SUPPORT \& POSTPARTUM DEPRESSION}

Polymorphisms of two loci at the oxytocin receptor gene in populations of Africa, Asia and South Europe. BMC Genetics, 17, 17. doi:10.1186/s12863-015-0323-8

Carter, C. S., \& Keverne, E. B. (2002). The neurobiology of social affiliation and pair bonding. In D. Pfaff (Ed.), Hormones, brain and behavior (pp. 299-337). San Diego, CA: Academic Press.

Chen, F. S., Barth, M., Johnson, S. L., Gotlib, I. H., \& Johnson, S. C. (2011). Oxytocin receptor (OXTR) polymorphisms and attachment in human infants. Frontiers in Psychology, 2, 200.

Chen, F. S., Kumsta, R., Dawans, B. V., Monakhov, M., Ebstein, R. P., \& Heinrichs, M. (2011). Common oxytocin receptor gene (OXTR) polymorphism and social support interact to reduce stress in humans. Proceedings of the National Academy of Sciences, 108(50), 19937-19942.

Cohen, S., Kamarck, T., \& Mermelstein, R. (1983). A global measure of perceived stress. Journal of Health and Social Behavior, 24(4), 385-396.

Cohen, S., \& Wills, T. A. (1985). Stress, social support, and the buffering hypothesis. Psychological Bulletin, 98(2), 310.

Collins, N. L., Dunkel-Schetter, C., Lobel, M., \& Scrimshaw, S. C. (1993). Social support in pregnancy: psychosocial correlates of birth outcomes and postpartum depression. Journal of Personality and Social Psychology, 65(6), 1243-1258.

Cornelis, M. C., Glymour, M. M., Chang, S. C., Tchetgen, E. J. T., Liang, L., Koenen, K. C., \& Kubzansky, L. D. (2012). Oxytocin receptor (OXTR) is not associated with optimism in the Nurses' Health Study. Molecular Psychiatry, 17(12), 1157. 


\section{OXTR, SOCIAL SUPPORT \& POSTPARTUM DEPRESSION}

Cox, J.L., Holden, J.M., \& Sagovsky, R. (1987). Detection of postnatal depression. Development of the 10-item Edinburg Postnatal Depression Scale. The British Journal of Psychiatry, $150(6), 782-786$.

Dennis, C. L., \& Chung- Lee, L. (2006). Postpartum depression help- seeking barriers and maternal treatment preferences: A qualitative systematic review. Birth, 33(4), 323-331.

Ditzen, B., Schaer, M., Gabriel, B., Bodenmann, G., Ehlert, U., \& Heinrichs, M. (2009). Intranasal oxytocin increases positive communication and reduces cortisol levels during couple conflict. Biological Psychiatry, 65(9), 728-731.

Domes, G., Heinrichs, M., Michel, A., Berger, C., \& Herpertz, S. C. (2007). Oxytocin improves "mind reading" in humans. Biological Psychiatry, 61(6), 731-733.

Doss, B. D., Rhoades, G. K., Stanley, S. M., \& Markman, H. J. (2009). The effect of the transition to parenthood on relationship quality: an 8-year prospective study. Journal of Personality and Social Psychology, 96(3), 601.

Duncan, L. E., \& Keller, M. C. (2011). A critical review of the first 10 years of candidate geneby-environment interaction research in psychiatry. American Journal of Psychiatry, $168(10), 1041-1049$.

Feldman, P. J., Dunkel-Schetter, C., Sandman, C. A., \& Wadhwa, P. D. (2000). Maternal social support predicts birth weight and fetal growth in human pregnancy. Psychosomatic Medicine, 62(5), 715-725.

Gong, P., Fan, H., Liu, J., Yang, X., Zhang, K., \& Zhou, X. (2017). Revisiting the impact of OXTR rs53576 on empathy: A population-based study and a meta-analysis. Psychoneuroendocrinology, 80, 131-136. 


\section{OXTR, SOCIAL SUPPORT \& POSTPARTUM DEPRESSION}

Hahn-Holbrook, J., Dunkel Schetter, C., Chander, A., \& Hobel, C. (2013). Placental corticotropin-releasing hormone mediates the association between prenatal social support and postpartum depression. Clinical Psychological Science, 1(3), 253-265.

Hahn-Holbrook, J., Cornwell-Hinrichs, T., \& Anaya, I. (2018). Economic and health predictors of national postpartum depression prevalence: A systematic review, meta-analysis, and meta-regression of 291 studies from 56 countries. Frontiers in Psychiatry, 8, 248, doi: 10.3389/fpsyt.2017.00248.

Hahn-Holbrook, J., Holt-Lunstad, J., Holbrook, C., Coyne, S. M., \& Lawson, E. T. (2011). Maternal defense: breast feeding increases aggression by reducing stress. Psychological Science, 22(10), 1288-1295.

Holt-Lunstad, J., Smith, T. B., \& Layton, J. B. (2010). Social relationships and mortality risk: a meta-analytic review. PLoS Med, 7(7).

Hostinar, C. E., Cicchetti, D., \& Rogosch, F. A. (2014). Oxytocin receptor gene polymorphism, perceived social support, and psychological symptoms in maltreated adolescents. Development and Psychopathology, 26(2), 465-477.

Iles, J., Slade, P., \& Spiby, H. (2011). Posttraumatic stress symptoms and postpartum depression in couples after childbirth: the role of partner support and attachment. Journal of Anxiety Disorders, 25(4), 520-530.

Insel, T. R. (2010). The challenge of translation in social neuroscience: a review of oxytocin, vasopressin, and affiliative behavior. Neuron, 65(6), 768-779.

James, C., Panford-Walsh, R., Birnboim, H. C., \& Iwasiow, R. (2013). Comparison of DNA yield from saliva and blood. Unpublished white paper, DNA Genotek. 


\section{OXTR, SOCIAL SUPPORT \& POSTPARTUM DEPRESSION}

Kim, H. S., Sherman, D. K., Sasaki, J. Y., Xu J., Chu, T. Q., Ryu, C., Suh, E. M., Graham, K., \& Taylor, S. E. (2010). Culture, distress and oxytocin receptor polymorphism (OXTR) interact to influence emotional support seeking. Proceedings of the National Academy of Sciences, 107, 15717-15721.

Kosfeld, M., Heinrichs, M., Zak, P. J., Fischbacher, U., \& Fehr, E. (2005). Oxytocin increases trust in humans. Nature, 435(7042), 673-676.

Labuschagne, I., Phan, K. L., Wood, A., Angstadt, M., Chua, P., Heinrichs, M., Stout, J. C., \& Nathan, P. J. (2010). Oxytocin attenuates amygdala reactivity to fear in generalized social anxiety disorder. Neuropsychopharmacology, 35, 2403-2413.

Li, J., Zhao, Y., Li, R., Broster, L. S., Zhou, C., \& Yang, S. (2015). Association of oxytocin receptor gene (OXTR) rs53576 polymorphism with sociality: a meta-analysis. PLoS One, 10, e0131820.

Lin, P. I., Vance, J. M., Pericak-Vance, M. A., \& Martin, E. R. (2007). No gene is an island: the flip-flop phenomenon. The American Journal of Human Genetics, 80, 531-538.

Ludmer, J. A., Jamieson, B., Gonzalez, A., Levitan, R., Kennedy, J., Villani, V., Masellis, M., Basile, V. S., \& Atkinson, L. (2017). Maternal DRD2, SLC6A3, and OXTR genotypes as potential moderators of the relation between maternal history of care and maternal cortisol secretion in the context of mother-infant separation. Biological Psychology, 129, $154-164$.

Ludmer, J. A., Levitan, R., Gonzalez, A., Kennedy, J., Villani, V., Masellis, M., \& Atkinson, L. (2015). DRD2 and SLC6A3 moderate impact of maternal depressive symptoms on infant cortisol. Psychoneuroendocrinology, 62, 243-251. 


\section{OXTR, SOCIAL SUPPORT \& POSTPARTUM DEPRESSION}

McCall, C., \& Singer, T. (2012). The animal and human neuroendocrinology of social cognition, motivation and behavior. Nature neuroscience, 15(5), 681.

McQuaid, R. J., McInnis, O. A., Stead, J. D., Matheson, K., \& Anisman, H. (2013). A paradoxical association of an oxytocin receptor gene polymorphism: early-life adversity and vulnerability to depression. Frontiers in Neuroscience, 7.

Milgrom, J., Gemmill, A. W., Bilszta, J. L., Hayes, B., Barnett, B., Brooks, J., \& Buist, A. (2008). Antenatal risk factors for postnatal depression: a large prospective study. Journal of Affective Disorders, 108(1), 147-157.

Mizumoto, Y., Kimura, T., \& Ivell, R. (1997). A genomic element within the third intron of the human oxytocin receptor gene may be involved in transcriptional suppression. Molecular and Cellular Endocrinology, 135, 129-138.

Mojaverian, T. \& Kim, H. S. (2013). Interpreting a helping hand: cultural variation in the effectiveness of solicited and unsolicited social support. Personality and Social Psychology Bulletin, 39, 88-99.

Netsi, E., Pearson, R. M., Murray, L., Cooper, P., Craske, M. G., \& Stein, A. (2018). Association of persistent and severe postnatal depression with child outcomes. JAMA Psychiatry, 75(3), 247-253

O'Hara, M. W., \& Swain, A. M. (1996). Rates and risk of postpartum depression-a metaanalysis. International Review of Psychiatry, 8(1), 37-54.

Poulin, M. J., Holman, E. A., \& Buffone, A. (2012). The neurogenetics of nice: receptor genes for oxytocin and vasopressin interact with threat to predict prosocial behavior. Psychological science, 23(5), 446-452. 


\section{OXTR, SOCIAL SUPPORT \& POSTPARTUM DEPRESSION}

Riem, M. M., Pieper, S., Out, D., Bakersman-Kranenburg, M. J., \& Ijzendoorn, M. H. (2010). Oxytocin receptor gene and depressive symptoms associated with physiological reactivity to infant crying. Social Cognitive and Affective Neuroscience, 6(3), 294-300.

Robertson, E., Grace, S., Wallington, T., \& Stewart, D. E. (2004). Antenatal risk factors for postpartum depression: a synthesis of recent literature. General Hospital Psychiatry, 26(4), 289-295.

Rodrigues, S. M., Saslow, L. R., Garcia, N., John, O. P., \& Keltner, D. (2009). Oxytocin receptor genetic variation relates to empathy and stress reactivity in humans. Proceedings of the National Academy of Sciences, 106(50), 21437-21441.

Saphire-Bernstein, S., Way, B. M., Kim, H. S., Sherman, D. K., \& Taylor, S. E. (2011). Oxytocin receptor gene (OXTR) is related to psychological resources. Proceedings of the National Academy of Sciences, 108(37), 15118-15122.

Sturge-Apple, M. L., Cicchetti, D., Davies, P. T., \& Suor, J. H. (2012). Differential susceptibility in spillover between interparentalconflict and maternal parenting practices: evidence for OXTR and 5-HTT genes. Journal of Family Psychology, 26(3), 431-442.

Thompson, R. J., Parker, K. J., Hallmayer, J. F., Waugh, C. E., \& Gotlib, I. H. (2011). Oxytocin receptor gene polymorphism (rs2254298) interacts with familial risk for psychopathology to predict symptoms of depression and anxiety in adolescent girls. Psychoneuroendocrinology, 36(1), 144-147.

Tost, H., Kolachana, B., Hakimi, S., Lemaitre, H., Verchinski, B. A., Mattay, V. S., ... \& MeyerLindenberg, A. (2010). A common allele in the oxytocin receptor gene (OXTR) impacts prosocial temperament and human hypothalamic-limbic structure and function. Proceedings of the National Academy of Sciences, 107(31), 13936-13941. 


\section{OXTR, SOCIAL SUPPORT \& POSTPARTUM DEPRESSION}

Turner, R. J., Frankel, B. G., \& Levin, D. M. (1983). Social support: conceptualization, measurement, and implications for mental health. In J. R. Greenley (Ed.), Researching community and mental health (Vol. 3, pp. 67-111). Greenwich, CT: JAI Press.

Turner, R. J., Grindstaff, C. F., \& Phillips, N. (1990). Social support and outcomes in teenage pregnancy. Journal of Health and Social Behavior, 31, 43-57.

Uchino, B. N. (2006). Social support and health: a review of physiological processes potentially underlying links to disease outcomes. Journal of behavioral medicine, 29(4), 377-387.

Windle, R. J., Shanks, N., Lightman, S. L., \& Ingram, C. D. (1997). Central oxytocin administration reduces stress-induced corticosterone release and anxiety behavior in rats. Endocrinology, 138, 2829-2834.

Wisner, K.L., Parry, B.L., \& Piontek, C.M. (2002). Clinical Practice. Postpartum Depression. The New England Journal of Medicine, 347(3), 194-199.

Yim, I. S., Tanner Stapleton, L. R., Guardino, C. M., Hahn-Holbrook, J., \& Dunkel Schetter, C. (2015). Biological and psychosocial predictors of postpartum depression: systematic review and call for integration. Annual Review of Clinical Psychology, 11, 99-137. 
OXTR, SOCIAL SUPPORT \& POSTPARTUM DEPRESSION

Table 1

Associations between demographic factors, OXTR genotype, social support and postpartum depression symptoms

\begin{tabular}{lccccc}
\hline \multicolumn{1}{c}{ Variable } & Mean & & Father & Mother & Family \\
& $(\mathrm{SE}) / \%(\mathrm{~N})$ & EPDS Score & Support & Support & Support \\
\hline Infant Age (months) & $6.01(0.22)$ & -0.03 & -0.06 & -0.09 & $\beta / \%$ \\
Maternal Age (years) & $33.14(0.37)$ & -0.06 & 0.07 & $-0.15^{*}$ & -0.08 \\
Income & $4.50(0.15)$ & -0.08 & $0.16^{*}$ & $0.16^{*}$ & 0.05 \\
Married & $81 \%$ & -0.04 & $0.31^{* * *}$ & 0.09 & $0.18^{* *}$ \\
Perceived Stress & $14.64(6.44)$ & $0.733^{* * *}$ & $-.21^{* *}$ & $-.27 * * *$ & $-.26^{* * *}$ \\
rs53576 Genotype & & & & & \\
\multicolumn{1}{c}{ AA } & $18 \%(39)$ & $6.15(4.15)$ & $25.56(3.91)$ & $24.16(4.60)$ & $25.46(2.52)$ \\
AG & $46 \%(101)$ & $7.60(4.57)$ & $25.69(3.27)$ & $24.67(4.20)$ & $24.90(3.41)$ \\
GG & $36 \%(80)$ & $6.25(4.41)$ & $25.86(4.05)$ & $24.62(4.85)$ & $25.21(4.05)$ \\
rs2268498 Genotype & & & & & \\
CC & $15 \%(32)$ & $6.06(4.06)$ & $24.92(5.23)$ & $25.68(3.46)$ & $26.16^{\mathrm{a}}(2.38)$ \\
CT & $48 \%(105)$ & $7.44(4.48)$ & $26.20(2.36)$ & $24.05(4.77)$ & $24.62^{\mathrm{b}}(3.77)$ \\
TT & $37 \%(83)$ & $6.61(4.42)$ & $25.53(4.32)$ & $24.72(4.62)$ & $25.40(3.57)$ \\
\hline
\end{tabular}

Note. ${ }^{\mathrm{t}}=\mathrm{p}<.10 ;{ }^{*}=\mathrm{p}<.05, * *=\mathrm{p}<.01, * * *=\mathrm{p}<.001 ;$ Values with different superscripts within the same row are significantly different from one another $(\mathrm{p}<.05)$; household income is coded as $1=$ less than $\$ 10,000 ; 2$ $=\$ 10,000-\$ 49,999 ; 3=\$ 50,000-\$ 74,999 ; 4=\$ 75,000-\$ 99,999 ; 5=\$ 100,000-\$ 149,999 ; 6=\$ 150,000-\$ 199,999$; $7=\$ 200,000-\$ 299,999 ; 8=\$ 300,000-\$ 399,999 ; 9=\$ 400,000-\$ 499,999 ; 10=$ over $\$ 500,000$. 
OXTR, SOCIAL SUPPORT \& POSTPARTUM DEPRESSION

Table 2

Correlation Matrix of the Association between Sources of Social Support and Postpartum Depression Symptoms

\begin{tabular}{lcccc}
\hline & $\begin{array}{c}\text { Total } \\
\text { Support }\end{array}$ & $\begin{array}{c}\text { Mother } \\
\text { Support }\end{array}$ & $\begin{array}{c}\text { Family } \\
\text { Support }\end{array}$ & $\begin{array}{c}\text { Baby's Father } \\
\text { Support }\end{array}$ \\
\hline & Pearson's r $(p)$ & Pearson's r $(p)$ & Pearson's r $(p)$ & Pearson's r $(p)$ \\
\hline EPDS Score & $-0.292(.000)$ & $-0.177(.010)$ & $-0.257(.000)$ & $-0.239(.000)$ \\
Mother Support & - & - & $.450(.000)$ & $.115(.095)$ \\
Family Support & - & - & - & $.456(.000)$ \\
\hline
\end{tabular}


OXTR, SOCIAL SUPPORT \& POSTPARTUM DEPRESSION

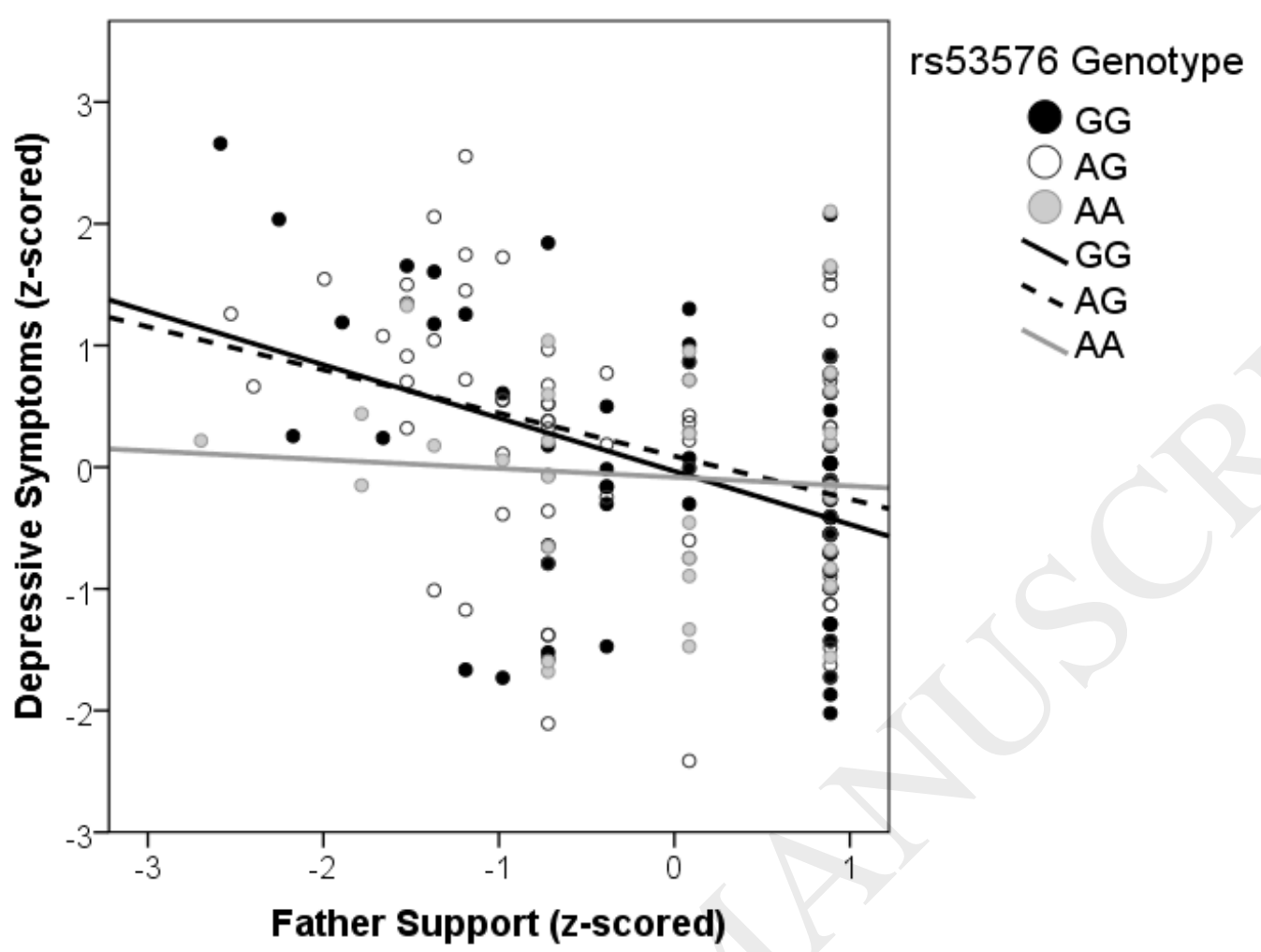

Figure 1. Association between depressive symptoms and father support, as moderated by OXTR rs53576 genotype. OXTR rs53576 genotype significantly moderated the effect of father support on postpartum depression risk. Father support was a more potent predictor of depressive symptoms in mothers with more G alleles. Simple effects tests showed that father support and depressive symptoms were significantly inversely correlated amongst GG and AG genotypes; whereas there was not a significant relationship in AA genotypes. ( $r^{2}$ values and correlations represent raw data without covariate adjustment. Covariate adjusted coefficients and effect sizes are reported in the results section.) 